\title{
BMJ Open Health professionals' perceptions of weight loss programmes and recommendations for future implementation: a qualitative study
}

\author{
Christina Jessen-Winge (D) , ${ }^{1,2}$ Pia Marie Ilvig, ${ }^{1}$ Trine Thilsing, ${ }^{1}$ Kim Lee, ${ }^{1}$ \\ Heather Fritz, ${ }^{3}$ Jeanette Reffstrup Christensen ${ }^{1}$
}

To cite: Jessen-Winge $C$, Ilvig PM, Thilsing T, et al. Health professionals' perceptions of weight loss programmes and recommendations for future implementation: a qualitative study. BMJ Open 2020;10:e039667. doi:10.1136/ bmjopen-2020-039667

- Prepublication history for this paper is available online. To view these files, please visit the journal online (http://dx.doi. org/10.1136/bmjopen-2020039667).

Received 22 April 2020 Revised 12 0ctober 2020 Accepted 20 October 2020
Check for updates

(C) Author(s) (or their employer(s)) 2020. Re-use permitted under CC BY-NC. No commercial re-use. See rights and permissions. Published by BMJ.

${ }^{1}$ Department of Public Health, University of Southern Denmark Faculty of Health Sciences, Odense, Denmark

${ }^{2}$ Department of Health, University College Copenhagen, Kobenhavn, Denmark

${ }^{3}$ Department of occupational therapy, Wayne State University, Detroit, Michigan, USA

Correspondence to Christina Jessen-Winge; cwinge@health.sdu.dk

\section{ABSTRACT}

Objective Obesity is an increasing public health challenge and most weight loss programmes are still inadequate to support sustainable weight loss. One reason for the continued lack of success might be the dominant biomedical, individualised approach to weight loss. Holistic approaches that focus on overall health and well-being in addition to weight loss are increasingly recommended. In Denmark, health professionals in the municipalities are responsible for developing and conducting weight loss programmes. The objective of this study was to explore what health professional's perceived as an ideal, holistic weight loss programme that could be feasibly implemented in the municipalities.

Design A phenomenological-hermeneutical qualitative study was performed using semistructured interviews. Setting Thirty-two Danish municipalities were weight loss programmes are developed and conducted.

Participants Thirty-five health professionals with experience conducting weight loss programmes.

Results Three themes emerged from the analysis: Support from the social network are important both during and after a weight loss, Changing the self-belief by positive discussions and doing activities, Maintaining changes through daily life.

Conclusion Future municipal weight loss programmes should emphasise overall health and well-being instead of weight loss and adopt a holistic approach including a focus on social relationships, meaningful activities and successes as part of a balanced daily life.

\section{BACKGROUND}

Obesity is associated with health risks including type 2 diabetes, heart disease and stroke. ${ }^{1}$ Individuals with obesity may experience that being obese negatively affects quality of life because of difficulties in performing necessary and valued everyday activities and a feeling of being stigmatised. ${ }^{2}{ }^{3}$ The Obesity Society first acknowledged obesity as a disease in 2008, and since then, obesity has been regarded as a chronic condition. ${ }^{4}$ The frontline non-pharmacological treatments for obesity focus on dietary changes, physical
Strengths and limitations of this study

- This study identified the perceptions of 35 health professionals conducting heterogenic programmes across the municipalities in Denmark, resulting in a diverse range of desires and experiences.

- This study only included participants from Denmark and therefore excludes perspectives of health professionals from other countries.

- The structured interviews were conducted by six different interviewers.

exercise and the use of behavioural therapy. ${ }^{56}$ Previous decades have seen a proliferation of programmes focused on diet, exercise and behavioural therapy and the programmes have succeeded in short term weight losses, but most weight losses are not maintained long term. ${ }^{7}$

There are multiple plausible causes for the lack of efficacy. One potential problem is that the programmes mainly focus on biomedical, individual approaches in the sense of avoiding diseases. ${ }^{56}$ This approach has been criticised for contributing to eating disorders, body dissatisfaction, low self-esteem and stigmatisation. ${ }^{8}$ Obesity is influenced by multiple interrelated physical, emotional and social components of everyday life. ${ }^{9}$ Programmes emphasising a holistic approach, including physical, emotional and social components in everyday, has resulted in weight loss and weight loss maintenance. ${ }^{10}{ }^{11}$ However, such approaches are few and more research on holistic approaches to decrease and maintain weight is needed. ${ }^{9}$

Obesity is also a growing problem in Denmark as $47.4 \%$ of the population is estimated to be overweight or obese. ${ }^{12}$ Based on the lack of weight loss maintenance the National Board of Health recommends that weight loss programmes focus on more 
holistic approaches by addressing psychosocial and daily life factors. ${ }^{13}$ The Danish healthcare system is free for all and funded by taxes. The obesity treatment system is divided into two parts. Individuals with body mass index (BMI) +40 combined with other lifestyle-related diseases are treated in regional specialised units at hospitals. Regional municipalities are also responsibility for health promotion and prevention services for citizens at risk for lifestyle diseases (often people with a BMI between 25 and 40). ${ }^{14}$ The municipal services are typically delivered through municipal health centres and general practice (GP) clinics. The municipal health centres offer weight loss programmes to citizens, when a citizen is referred by their GP. ${ }^{14}$

The health professionals (HP) at each municipality develop and conduct their own health promotion and prevention weight loss programmes. These programmes have been shown to be heterogenic across the municipalities in terms of length, dose and content. Most programmes include content related to diet and/or exercise, but few focus on the physical, emotional and social components in everyday life, which are recommended by the Danish National Board of Health. ${ }^{15}$ Even though the Danish municipalities have not evaluated their weight loss programmes evidence from international research has shown a lack of efficacy in municipal weight loss programmes. ${ }^{16}$ Therefore, it seems possible that the same would be the case in Denmark.

To address the challenge with poor weight loss maintenance and that Danish weight loss programmes across the municipalities are heterogenic, our long-term goal is to develop an evidence-based programme that supports people with overweight and obesity to change their daily life while losing weight. In our prior research, ${ }^{15}$ we examined the desires of people with obesity regarding what they believe would be important to include in a weight loss programme. HP would ultimately be involved in the implementation of any future programme. HP also have expertise and perspectives regarding the development and conducting weight loss programmes in the municipalities. The objective of this study was to explore what HP's perceived as an ideal, holistic weight loss programme that could be feasibly implemented in the municipalities.

\section{METHODS}

We conducted a qualitative study based on a phenomenological-hermeneutical approach. A phenomenological approach requires that the researchers put aside their assumptions and ideas in order to capture a rich description of the phenomenon in focus,${ }^{17}$ whereas the hermeneutical approach is more interpretative. ${ }^{17}$ We used both approaches because we wanted to reach a description and an interpretation of the experiences from the HP.

\section{Settings and participants}

We selected HP through purposeful sampling from all the 98 Danish municipalities. To be included in the study the HP had to have conducted group-based municipal weight loss programmes previously at least three times to ensure they had prior experience. We excluded HP if they conducted weight loss programmes for people with a specific disease like diabetes because the content was expected to be slightly different than programmes only related to weight loss. We sent potential participants an invitation by email with the inclusion criteria and information about the overall aim of the project. We also informed potential participants that we would contact them by phone within a week to give additional verbal information about the study. If a potential participant declined to participate by email, they were not contacted further. If we were unable to reach the HP after two attempts (a week apart) they were not included in the study.

\section{Data collection}

We conducted semistructured individual interviews with each professional one at a time and in a location of their choice. ${ }^{18}$ All the participants chose their workplace. The number of interviews was guided by data saturation. ${ }^{19}$ The interview guide was divided into two sections. The first section contained questions about the professionals' current practice by asking them to describe the content and their perspectives of the weight loss programmes they conducted with special attention to daily lives and social contexts. The first section of the guides was influenced by the knowledge generated from our prior research and interviews with people with obesity. ${ }^{15}$ In the second section, the HP were asked about what they would recommend for a future weight loss programme by asking 'If no limits existed what would you include in a municipal weight loss programme?' (box 1). The interview guide was pilot tested leading to a rearrangement of some of the questions.

The interviews were conducted by the first author, who is also a PhD student and five female Master of Occupational Therapy students. The first author was an experienced interviewer and the master's students were trained and evaluated for competency by the first and the last author prior to conducting the interviews. The interviews were conducted in Danish between January and March 2019 and lasted between 40 and $70 \mathrm{~min}$. All interviews were audiorecorded and each interviewer transcribed their own interviews.

\section{Data analysis}

The data were analysed using qualitative content analysis to understand the multifaceted descriptions from the participants. ${ }^{20} 21$ The analysis was systematic and focused on the manifest and latent content by moving from the concrete level to a more abstract and general level. ${ }^{22}$ The analysis consisted of four steps as described by Graneheim and Lundman. ${ }^{20}$ In the first step, all the data materials 


\section{Box 1 Interview guide}

\section{Interview Questions}

Content of the current weight loss programme

- Please describe the weight loss programme from beginning to end.

The importance of the topics to the participants

- How do the participants understand the topics in the programme?

- What meaning do the topics have for the participants and how do you process the meaning?

How do you support the participants in changing their habits?

Do you focus on the participants' daily activities? And how do you include them in the programme?

The belief in success

- How significantly are the participants own believe in their success in losing weight?

How is the participants self-image?

Do they believe that success affects their weight loss?

- How does it affect their programme?

The importance of social relations to lose weight

-What considerations do you have regarding group compositions?

What do you do to support the unity of the groups?

Do you include close relations?

- If yes, how do you include the close relations?

- How do you consider if the close relations are important for the weight loss?

The optimal weight loss programme

- What is your most positive experience while carrying out weight loss programmes?

-What do you find necessary to include in a weight loss programme?

- If no limits existed how would you plan and carry out a municipal weight loss programme?

were read by three of the authors (CJ-W, KL and JRC). In the second step, the content related to the aim of the study was identified and divided into meaning units. In the third step, the meaning units were condensed and labelled with a code. Aggregation of codes resulted in 14 subcategories, which were further aggregated into six categories. At this stage, we reached manifest knowledge from the text. ${ }^{20}$ In the final step, the six categories were grouped under three themes with subthemes to reach the latent and more general knowledge of the text. Three authors (CJ-W, KL and JRC) made the decisions about categories and subsequent themes by discussion and consensus (table 1). A native English scientific writer who also spoke Danish, translated the quotes from Danish to English.

\section{Patients and public involvement statement}

Due to the design of this study, no HP were involved in planning or conducting the study. The study focused on perspectives of professionals. The results will be discussed with people with obesity and HP when developing the evidence-based weight loss programme.

\section{RESULTS}

The 42 HP interviewed had a mean number of 5.4 years of experience conducting weight loss programmes. Seven of the interviews were excluded as these did not fulfil the inclusion criteria. Despite these exclusions data saturation was obtained. The 35 included HP are presented in figure 1 .

The programmes were all group-based but different regarding HP, dose and specific content. See table 2 for more details.

The analysis resulted in three themes, each with subthemes that reflected the HP' perceived experiences with delivering weight loss programmes and their wishes for future programmes: (1) Support from the social network is important both during and after a weight loss (subthemes positive support from family and friends are associated with better results, encouraging peer support both within and outside the group context). (2) Changing the self-belief by positive discussions and doing activities (subthemes reviewing success through goals and small steps, skill training to support success). (3) Maintaining changes through daily life (subthemes awareness of habit patterns, value through activities and communities).

\section{Support from the social network is important both during and after weight loss}

All the HP agreed that the support from the social network was important in the weight loss process. They described that the most important support should come

Table 1 An example of the process from meaning units to theme development 'Support from the social network are important both during and after a weight loss'

\begin{tabular}{|c|c|c|c|c|c|}
\hline Meaning units & $\begin{array}{l}\text { Condensed } \\
\text { meaning units }\end{array}$ & Codes & Subcategories & Categories & Themes \\
\hline $\begin{array}{l}\text { 'I believe that those who have a husband or wife } \\
\text { who gives } 100 \% \text { support... if they come tired home } \\
\text { (the husband or wife) will tell them that they will } \\
\text { open the door for them because they have to go for } \\
\text { a run or go biking... Of course, they have a better } \\
\text { chance for success'. }\end{array}$ & $\begin{array}{l}\text { The once with } \\
\text { supportive network } \\
\text { at home have a } \\
\text { better chance for } \\
\text { success }\end{array}$ & $\begin{array}{l}\text { Support } \\
\text { from home } \\
\text { results in } \\
\text { success }\end{array}$ & $\begin{array}{l}\text { Supportive close } \\
\text { network gives } \\
\text { success }\end{array}$ & $\begin{array}{l}\text { The support } \\
\text { from others is } \\
\text { essential }\end{array}$ & $\begin{array}{l}\text { Support from the } \\
\text { social network are } \\
\text { important both } \\
\text { during and after a } \\
\text { weight loss }\end{array}$ \\
\hline
\end{tabular}




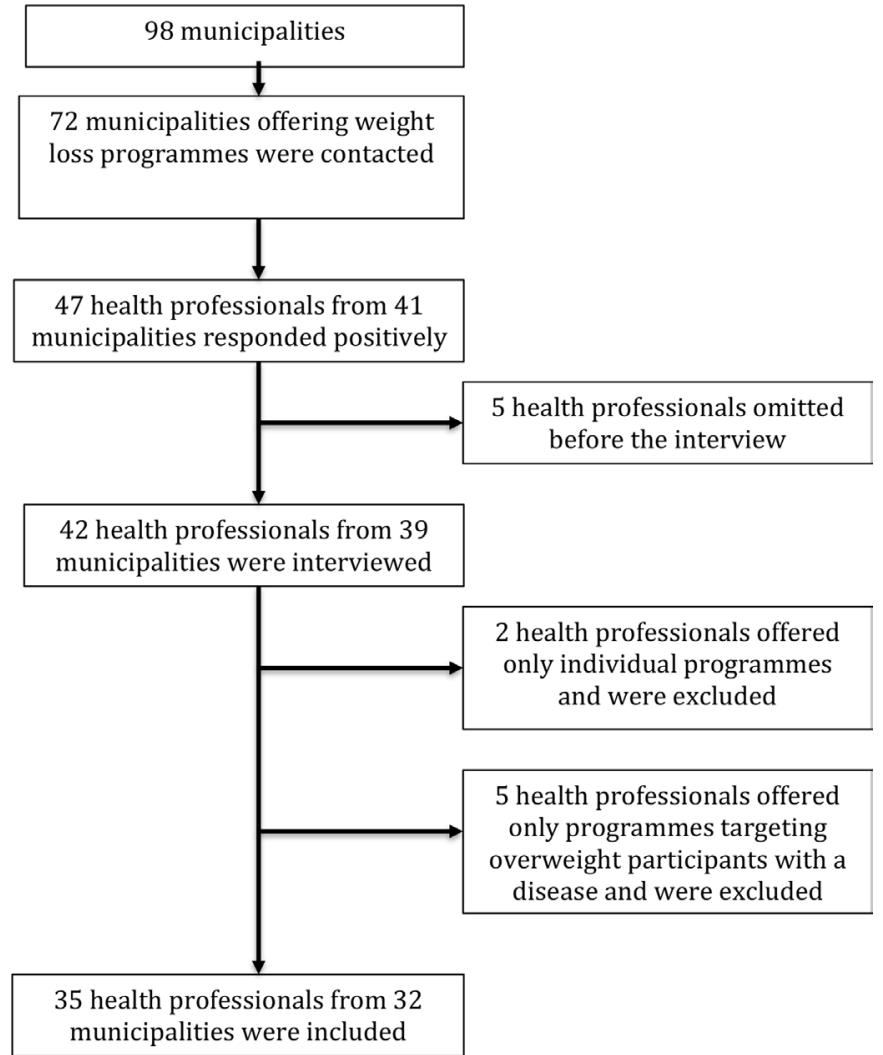

Figure 1 Flowchart of participant selection.

from friends and family, or from peers who were also a part of the weight loss group.

Positive support from family and friends are associated with better results

Regarding friends and family, they discussed that when relatives or friends 'jumped on the same train' in relation to eating and exercise patterns, it often resulted in greater success. The HP discussed two primary ways that the support of friends and family was helpful to the weight loss process. The first involved friends or couples joining the programmes together. In the HP' experience, these joint efforts resulted in greater weight losses, as one HP expressed:

I have two couples in one of the groups right now and they have really changed a lot becausethey have the social part together.

The second involved simply having a friend or family that was committed to support. This person acted as cheerleader and could also increase adherence with weight loss goals, as the following quote illustrates.

I believe that those who have a husband or wife who gives $100 \%$ support... if they come home tired [the husband or wife] will tell them that they will open the door for them because they have to go for a run or go biking... Of course, they have a better chance of success.
Table 2 Overview of health professionals, sessions and content in the programmes

\begin{tabular}{ll}
\hline The programme & Number \\
\hline $\begin{array}{l}\text { Health professionals } \\
\text { Dietitians or other nutrition } \\
\text { professionals }\end{array}$ & 25 professionals \\
Physiotherapist & 4 professionals \\
\hline Occupational therapist & 2 professionals \\
\hline Health coach & 4 professionals \\
\hline Number of sessions & \\
\hline $5-10$ sessions & 21 programmes \\
\hline $11-15$ sessions & 8 programmes \\
\hline $16-20$ sessions & 4 programmes \\
\hline More than 20 sessions & 2 programmes \\
\hline Content-group discussions & \\
\hline Diet & 26 programmes \\
\hline Exercise & 16 programmes \\
\hline Habits & 24 programmes \\
\hline Sleep & 7 programmes \\
\hline Motivation & 18 programmes \\
\hline Content-group activities & 10 programmes \\
\hline Diet & 16 programmes \\
\hline Exercise & \\
\hline
\end{tabular}

The HP also provided examples of strategies they used to relate to participants how different types of social support could either hinder or help their weight-loss efforts. For example, one HP used a traffic light metaphor. The 'green' people respected the wishes for change and supported the participants by changing routines when they met (eg, by serving vegetables instead of cake). Conversely, the 'red' people were characterised as frustrating and difficult because they were not supportive. Therefore, some participants reduced contact with specific groups of friends and in some cases, the lack of support during the weight loss process could even lead to divorce: 'It often happens that people leave them when they start this process.'

\section{Encouraging peer support both within and outside the group context}

While existing social networks were important, the HP also highlighted the importance of group-delivered programmes for increasing peer support through the creation of new networks. Group programmes provided an opportunity to be surrounded by others facing similar struggles and doubts. Within the group, peers supported each other, motivated each other and held each other accountable. One of the HP described the dynamic as magic:

I really think it is rewarding with the groups. You can see the dynamic (....) When they get to know each other and find a common frame...sometimes I stand there thinking "this is almost magical. 
HP encouraged lasting relationships between the peers. For example, they encouraged the participants to make Facebook accounts to keep on exchanging experiences and to have a platform for planning things together. Another way of supporting each other was the use of 'buddies' with the aim to have a person to call whenever things went wrong:

They make a contract and describes their goals for the next period and how the buddy can support them by doing this and that. And it works, yes it really does, so this is one of the things I would like to highlight.

Sometimes the groups resulted in friendships with people they could do things together with-things they earlier experienced as difficult. One HP gave an example of three girls who decided to buy a sports bra together which earlier had been difficult because they were on their own.

Though the HP unanimously supported the need for participants to get support from people in their close social networks, they also acknowledged that in some cases social relationships were detrimental to the weight loss process and should therefore be changed. One HP discussed her experiences with a participant who struggled with her weight loss due to pressure to act in ways that undermined her weight loss goal:

We are not individualist when we talk about healthy lifestyle. We are linked together in a lot of rings, which pull us in different directions...

\section{Changing the self-belief by positive discussions and doing activities}

The HP explained that many participants had rigid beliefs about how to lose weight and most often these beliefs impeded success. As such, they sought ways to challenge the participants' beliefs.

\section{Reviewing success through goal and small steps}

Rigid beliefs about how to successfully lose weight often resulted in feelings of guilt when the participant failed to adhere to what they perceived as a rule (eg, never eat cake again). In addition to challenging rigid beliefs, the HP tried to change the overall focus from losing weight to having a meaningful and satisfied life. Rather than allowing participants to dwell on feelings of guilt, they encouraged the participants to see their successes. Some HP found it useful to discuss 'the stages of change model $^{23}$ and show the participants that people are not always ready to change, and that it was okay not to be as ready as someone else. This gave the participants a sense of success even though they did not lose $10 \mathrm{~kg}$. In most programmes, they helped the participants set realistic goals to ensure that they were not setting themselves up for failure. In the weight loss process the HP also focused on the things that went well in the participants' attempts to reach a goal rather than focusing on what went wrong.
Those small successes also increased the participants' confidence in their own capacities.

You can plant the seed by giving them [the participants] some coping strategies. You can give them the experience of being able to do something they didn't think they could, which makes them want to do more.

\section{Skill training to support success}

The HP emphasised embracing both trial and error related to doing activities during the programme. They believed in the importance of doing things because 'you only learn by doing it'. They highlighted that they used activities as the basis of skill building to improve participants' beliefs in themselves. The HP discussed participants needed to have certain skills (eg, practical skills related to cooking or food shopping) to integrate recommendations into their daily life in the long term. The activities that were used most often related to either diet or exercise. For example, some of the HP invited participants to the municipality's health centre kitchen to learn how to cook healthy food. During such sessions, the participants could work through how they might adapt their own recipes and cooking styles to maintain their lost weight over time. Other examples included inviting participants to the supermarket to discuss the nutritional value of the groceries. Those activities were perceived to increase the awareness of healthy foods while also ensuring that the participants had the skills to successfully translate knowledge to their daily lives. As one HP stated:

I think it works - practical activities, because it gives a picture of their everyday lives and what they might be able to focus on, regarding the amount of sugar or vegetables.

\section{Maintaining changes through daily life}

The HP all discussed that the behaviour change process was a lifelong process. For behaviour changes to be maintained, they had to be integrated into daily life.

\section{Awareness of habit patterns}

The HP were attentive to how standardised recommendations needed to be tailored to the participants' unique life contexts. One professional noted:

There are the recommendations, but how does it fit into [the participants'] daily life. If it does not fit, then do something else.

To help the participants to integrate the recommendations into their daily life, they often coached the participants to look at their daily life patterns to find out what they could put into their life and what they should avoid doing. They encouraged the participants to be more aware of their habits because awareness was found to be the first step on the way to change. Even though the HP acknowledged that working with habits was relevant 
to weight loss, one of the HP thought it could be challenging because the participants were on their own:

Making them [the habits] visible can be difficult when we are not out there with them in everyday life, because habits are everything, it is not something one is aware of.

Some HP acknowledged that this level of reflection about one's everyday life took a lot of energy:

It demands a lot of energy in the daily life, it demands energy when you have to be aware of and think about 'what do I put in the shopping cart' and 'what situations occurs when I fill the cart with things I did not plan to buy'.

Thus, goal setting, action planning and homework were all designed to assist the participants in this difficult process.

\section{Values through activities and community}

The HP supported using concrete activities to support behaviour change. The HP often implemented activities for the entire group as part of a treatment session. Having a trusted HP present to guide the experience made it less intimidating for many participants and helped expose some participants to activities that they might not otherwise have attempted. One HP described activities as 'the steppingstone that support changes'. Another HP provided the following example of an outing in the dunes. The example illustrates how people may be concerned about trying something new at first, but once they complete an activity, their worries are often replaced with excitement and satisfaction.

Oh no, are we going though these dunes, it is way too long and did I remember my asthma medicine and things like that, but people are so satisfied when they get back. But it was actually great, and we had fresh air $(\ldots .$.$) .$

The HP highlighted that trying new activities or doing them in another way were important because they recognised that some participants struggled to find out what they really found enjoyable or motivating. The HP, therefore found it important to help the participants rediscover their interests, needs and values. For instance, one HP said:

Maybe they [the participants] find out that they keep on saying to them self that I have to get a membership for the fitness center. Or maybe I have a membership but never go down there, then we talk about what gives you joy, what gives you energy and what are your experiences?

Most HP desired to see more integration between the weight loss programmes and the community resources. They recognised that often, the participants struggled to maintain their weight loss after the programme ended because they had only taken the first step in finding values in new activities. Therefore, many HP voiced support for community-based resources that the participants could use to build on successes gained during the programmes: 'It is such a success to build this bridge for the participants so that they have something after the programme. It is a way to keep on the good lifestyle changes that they have started.'

\section{DISCUSSION}

This study reports on the findings of 35 interviews with HP conducting weight loss programmes in the Danish municipalities. The results suggest elements that HP felt should be included in an ideal municipal weight loss programme. Overall, our data suggest that the HP believed that maintaining weight loss was a lifelong process, which required an increase in self-efficacy, having support of friends and family, integration of changes in daily life and the development of new habits. It seemed essential to take away feelings of guilt by turning the focus away from weight loss. This is in line with new weight-neutral approaches such as health at every size (HAES) ${ }^{24}$ HAES takes a health perspective by focusing on intuitive eating, joyful physical activity and reducing stigma ${ }^{24}$ HAES is based on group discussions with fixed topics. The programme does not promote doing any activities to gain hand on experience, however. ${ }^{10}$ The HP in our study believed that doing activities was essential. There are three key reasons why activities are important in a weight loss programme. First, in line with John Dewey's seminal insights about learningby-doing it promote a deeper learning. ${ }^{25}$ According to Dewey the connection between one's activities and the consequences becomes embodied within the person as new knowledge. ${ }^{25}$ Second, doing activities support habit formation because the practical approach makes it easier implementing in daily life. ${ }^{26}$ Third, the participants experience positive feelings from the experience and supporting self-efficacy. Though several HP supported using activities, most activities were related to diet and/ or exercise. Daily life consist of a myriad of activities that could impact weight loss efforts. ${ }^{27}$ As such, focusing only on activities related to diet and exercise might result in an imbalance in daily life because changes made in one domain will affect other domains. ${ }^{27}$ For instance, if a woman starts exercising three times a week, she will have less time with her children. Thus, understanding how weight loss activities affect the whole balance of daily life should be part of a weight loss programme. Principles from an occupational therapy programmes called Lifestyle Redesign could support people with obesity finding this balance. Lifestyle Redesign is not a weight loss programme however the principles might be relevant translating to a weight loss programme as it support the participants to identify barriers and options in activities through self-analysing and reflections and are done in different activities during the programme. ${ }^{28}$ This combination support changes based on understandings about 
the relationship between occupation, health and wellbeing in one's daily life. ${ }^{28}$

The HP in this study also supported incorporating participant's social dimensions into treatment. It seems essential to include the nearest social network because people are embedded in the social world and experience has to be understood within the social context. ${ }^{29}$ It is increasingly acknowledged that the social network influences weight-related behaviour and that people with overweight or obesity seem to cluster in the same networks. ${ }^{30}$ One study by Bahr et al indicated that traditional weight loss programmes might fail because individuals will be drawn back to the original weight behaviour by the network clusters. ${ }^{31}$ Even though the HP recommend including partners and friends in the programme, those relationships may not always be conducive to weight loss efforts. Therefore Bahr et al recommend expanding the social context to go beyond the nearest network and including friend's friends too, and particularly those that could support future goals. This network-driven strategy might reverse the current challenges with the increasing number of people with overweight and obesity and support a large segment of the population to live a healthier life. ${ }^{31}$

\section{Strengths and limitations}

A limitation might be that the interviews were only done in Denmark which affects the extern validity. On the other hand, the relatively large sample suggests that the issues raised are salient across regions in Denmark.

The programmes included in this study are heterogenic in length, dose and content. We regard this as a strength because it reflects the heterogenic within clinical practice. It also includes different perspectives from a varied picture of the perceptions and wishes from the HP which is important in developing a new weight loss programme.

\section{CONCLUSION}

The HP emphasised that ideal weight loss programmes should turn their focus away from weight loss exclusively and instead focus on weight loss as integrated in overall health and daily life. They expanded this sphere by including a more holistic perspective by framing an ideal weight loss programme as one that focused on social relations, daily activities, habit change and positive success as part of a balanced daily life. Future weight loss programmes should emphasise a holistic approach to health and well-being instead of only losing weight.

Contributors CJ-W and JRC designed the study. CJ-W and $\mathrm{KL}$ were involved in the data analysis and CJ-W, KL, JRC and HF were involved in interpretation of the findings. CJ-W, PMI, TT, KL, HF and JRC were all involved in the manuscript drafting. CJ-W, HF and JRC wrote the first draft. CJ-W, PMI, TT, KL, HF and JRC have all approved the final version and agree to be count accountable for all aspects of the work.

Funding The authors have not declared a specific grant for this research from any funding agency in the public, commercial or not-for-profit sectors.

Competing interests None declared.
Patient consent for publication Not required.

Ethics approval Ethical approval was not necessary according to the 'The Regional Committees on Health Ethics for Southern Denmark'. However, in accordance with the Declaration of Helsinki signed informed consents were obtained prior to the interviews.

Provenance and peer review Not commissioned; externally peer reviewed.

Data availability statement Data are available upon reasonable request. All transcribed interviews can be provided in Danish on request.

Open access This is an open access article distributed in accordance with the Creative Commons Attribution Non Commercial (CC BY-NC 4.0) license, which permits others to distribute, remix, adapt, build upon this work non-commercially, and license their derivative works on different terms, provided the original work is properly cited, appropriate credit is given, any changes made indicated, and the use is non-commercial. See: http://creativecommons.org/licenses/by-nc/4.0/.

\section{ORCID iD}

Christina Jessen-Winge http://orcid.org/0000-0001-8323-8863

\section{REFERENCES}

1 World Health Organization. Global status report on noncommunicable diseases 2014, 2014. Available: http://apps.who. int/iris/bitstream/handle/10665/148114/9789241564854_eng.pdf; jsessionid=F6300A7390208391BB9BF30F5AD2A84A? sequence $=1$

2 Forhan MA, Law MC, Vrkljan BH, et al. The experience of participation in everyday occupations for adults with obesity. Can J Occup Ther 2010;77:210-8.

3 Kolotkin RL, Andersen JR. A systematic review of reviews: exploring the relationship between obesity, weight loss and health-related quality of life. Clin Obes 2017;7:273-89.

4 Jastreboff AM, Kotz CM, Kahan S, et al. Obesity as a disease: the obesity Society 2018 position statement. Obesity 2019;27:7-9.

5 Jensen MD, Ryan DH, Donato KA, et al. Executive summary: guidelines (2013) for the management of overweight and obesity in adults: a report of the American College of Cardiology/American heart association Task force on practice guidelines and the obesity Society published by the obesity Socie. Obes 2014;22:S5-39.

6 Burgess E, Hassmén P, Welvaert M, et al. Behavioural treatment strategies improve adherence to lifestyle intervention programmes in adults with obesity: a systematic review and meta-analysis. Clin Obes 2017;7:105-14.

7 Lv N, Azar KMJ, Rosas LG, et al. Behavioral lifestyle interventions for moderate and severe obesity: a systematic review. Prev Med 2017;100:180-93.

8 Carbonneau E, Bégin C, Lemieux S, et al. A health at every size intervention improves intuitive eating and diet quality in Canadian women. Clin Nutr 2017;36:747-54.

9 Brown J, Wimpenny P. Determining factors required for a holistic approach to weight management of those with obesity. ANS Adv Nurs Sci 2011;34:136-50.

10 Ulian MD, Pinto AJ, de Morais Sato P, et al. Effects of a new intervention based on the Health at Every Size approach for the management of obesity: The "Health and Wellness in Obesity" study. PLoS One 2018;13:1-19.

11 Albright AL, Gregg EW. Preventing type 2 diabetes in communities across the U.S.: the National diabetes prevention program. Am J Prev Med 2013;44:S346-51.

12 Sundhedsstyrelsen [The Danish National Board of Health]. Danskernes Sundhed - Den Nationale Sundhedsprofil 2017 [The Health of the Danish population - the national health profil 2017]. Sundhedsstyrelsen 2017:92-9.

13 Hjalsted B, Fischerman M, Finke K, et al. Forebyggelsespakke Overvægt. [Prevention package - overweight]. Sundhedsstyrelsen [The Danish National Board of Health] 2013.

14 The Ministry of Health. Healthcare in Denmark, an overview, 2016. Available: https://en.wikipedia.org/wiki/Healthcare_in_Denmark [Accessed 17 Aug 2020].

15 Jessen-Winge C, llvig PM, Jonsson $\mathrm{H}$, et al. Obesity treatment: a role for occupational therapists? Scand J Occup Ther 2020;60:1-8.

16 Booth HP, Prevost TA, Wright AJ, et al. Effectiveness of behavioural weight loss interventions delivered in a primary care setting: a systematic review and meta-analysis. Fam Pract 2014;31:643-53.

17 Birkler J. Videnskabsteori - en grundbog [Theory of Science basics]. Munksgaard Danmark 2005.

18 Brinkmann S, Kvale S. Interview: learning the craft of qualitative interviewing. Sage Publication, 2014. 
19 Saunders B, Sim J, Kingstone T, et al. Saturation in qualitative research: exploring its conceptualization and operationalization. Qual Quant 2018;52:1893-907.

20 Graneheim UH, Lundman B. Qualitative content analysis in nursing research: concepts, procedures and measures to achieve trustworthiness. Nurse Educ Today 2004;24:105-12.

21 Elo S, Kääriäinen M, Kanste O, et al. Qualitative content analysis. SAGE Open 2014;4:215824401452263.

22 Graneheim UH, Lindgren B-M, Lundman B. Methodological challenges in qualitative content analysis: a discussion paper. Nurse Educ Today 2017;56:29-34.

23 Werch CE, Ames S, Moore MJ, et al. Health behavior insights: the transtheoretical/stages of change model: Carlo C. DiClemente, PHD. Health Promot Pract 2009;10:41-8.

24 Bombak A. Obesity, health at every size, and public health policy. Am J Public Health 2014;104:e60-7.

25 Boydston J. Democracy and Education. The Middle Works of John Dewey, 1899 - 1924. Carbondale, IL: Southern Illinois University Press, 2008.
26 Cleo G, Hersch J, Thomas R. Participant experiences of two successful habit-based weight-loss interventions in Australia: a qualitative study. BMJ Open 2018;8:e020146-9.

27 Wilcock A, hocking C. An occupational perspective of health (Chapter 11). 3rd edn. Slack Incorporated, 2015.

28 Jackson J, Carlson M, Mandel D, et al. Occupation in lifestyle redesign: the well elderly study occupational therapy program. $A m \mathrm{~J}$ Occup Ther 1998;52:326-36.

29 Biesta GJJ, Burbules NC. Pragmatism and educational research. philosophy, theory, and educational research series. Rowan \& Littlefield Publishers, Inc, 2011.

30 Powell K, Wilcox J, Clonan A, et al. The role of social networks in the development of overweight and obesity among adults: a scoping review. BMC Public Health 2015;15:1-13.

31 Bahr DB, Browning RC, Wyatt HR, et al. Exploiting social networks to mitigate the obesity epidemic. Obesity 2009;17:723-8. 